\title{
Laser crystallization for large-area electronics
}

\author{
Toshiyuki Sameshima
}

Received: 21 August 2008 / Accepted: 4 November 2008 / Published online: 30 April 2009

(C) Springer-Verlag 2009

\begin{abstract}
Laser crystallization is reviewed for the purpose of fabrication of polycrystalline silicon thin film transistors (poly-Si TFTs). Laser-induced rapid heating is important for formation of crystalline films with a low thermal budget. Reduction of electrically active defects located at grain boundaries is essential for improving electrical properties of poly-Si films and achieving poly-Si TFTs with high performances. The internal film stress is attractive to increase the carrier mobility. Recent developments in laser crystallization methods with pulsed and continuous-wave lasers are also reviewed. Control of heat flow results in crystalline grain growth in the lateral direction, which is important for fabrication of large crystalline grains. We also report an annealing method using a high-power infrared semiconductor laser. High-power lasers will be attractive for rapid formation of crystalline films over a large area and activation of silicon with impurity atoms.
\end{abstract}

PACS $85.30 . \mathrm{Tv} \cdot 61.72 . \mathrm{Uf} \cdot 81.10 . \mathrm{Jt} \cdot 02.60 . \mathrm{Cb} \cdot 64.70 . \mathrm{D}-$

\section{Introduction}

Polycrystalline silicon thin film transistors (poly-Si TFTs) have been applied to switching elements for liquid-crystal flat-panel displays used in notebook-type personal computers, mobile phones and flat-panel televisions [1]. Poly-Si TFTs have also been applied to logical integrated circuits because of their possibility of a high operation frequency

T. Sameshima ( $\square)$

Tokyo University of Agriculture and Technology, 2-24-16,

Nakamachi, Koganei, Tokyo 184-8588, Japan

e-mail: tsamesim@cc.tuat.ac.jp
$[2,3]$. Fabrication of TFT circuits on plastic films is also attractive for cheap, flexible and light devices [4]. For this purpose, fabrication processes of TFTs at a low temperature are important because of low heat resistivity of glass and plastic substrate materials. The technologies of polycrystalline silicon thin film transistors (poly-Si TFTs) have been markedly developed in the last 20 years. Sameshima et al. developed excimer laser induced crystallization of amorphous silicon films formed on glass substrates [5]. They reported poly-Si TFTs using laser crystallization with a low processing temperature of $270^{\circ} \mathrm{C}$. Many works on pulsed laser crystallization have been done to improve the low temperature fabrication processing of poly-Si TFTs [6-8]. The equipment of crystallization has been developed using a pulsed excimer laser for production of poly-Si TFTs at the present stage. Furthermore, crystallization of silicon films in the lateral direction has been widely investigated in order to fabricate poly-Si TFTs with high performances.

In this paper, laser crystallization technology is reviewed for formation of poly-Si films at a low processing temperature. Structural and electrical properties of silicon films are discussed. Passivation of the $\mathrm{SiO}_{2} / \mathrm{Si}$ interface and grain boundaries is discussed for fabrication of TFTs with a high mobility and a low threshold voltage. Crystallization of silicon films in the lateral direction using a pulsed laser as well as a continuous-wave laser is also referred to for TFTs with high performances. Moreover, we also report infrared semiconductor induced crystallization of silicon. A high-power infrared laser can have an advantage of laser crystallization with a short tact time. We also discuss activation of silicon implanted with phosphorus or boron atoms using a semiconductor infrared laser. 


\section{Laser-induced heating followed by melting of silicon and germanium films}

Pulsed UV-laser light is effectively absorbed in the silicon surface because of a high absorption coefficient $\sim 10^{6} \mathrm{~S} / \mathrm{cm}$ of silicon at wavelengths lower than $350 \mathrm{~nm}$. The absorbed light simultaneously excites the electronic states of silicon. The energy of the excited states is relaxed to lattice vibration states within the time on the order of $10^{-12} \mathrm{~s}$ [9]. In the case of ns-order pulsed laser irradiation, lattice heat is, therefore, the most important interaction [10]. The heat energy generated at the surface region caused by light absorption diffuses into interior regions of silicon films. The high heat-diffusion coefficient of silicon allows heat diffusion into the underlying substrates. The heating characteristics of silicon films therefore depend on the thermal properties of the substrates $[10,11]$. In a case of silicon films formed on glass substrates, heating properties of the silicon films such as the threshold energy density for crystallization are therefore governed by the heat diffusivity, the density and the specific heat of the glass substrates. The low heat diffusivity at $\sim 1.4 \mathrm{~W} / \mathrm{mK}$ of glass results in localization of heat energy at a surface region about 300-nm deep during laser irradiation [12]. The system of silicon film/glass substrate gives an essential advantage of a low energy required for crystallization of silicon films.

Transient conductance measurements are useful to observe rapid melting and solidification phenomena [13, 14]. Figure 1a shows the transient electrical conductance per unit area when a pulsed $\mathrm{XeCl}$ excimer laser with a pulse width of $30 \mathrm{~ns}$ was irradiated to 50-nm-thick Si films formed on a quartz substrate [15]. A laser energy density higher than $200 \mathrm{~mJ} / \mathrm{cm}^{2}$ was necessary to observe a significant increase in the electrical conductivity because of the high melting point of silicon films. The electrical conductance rapidly increased from $10 \mathrm{~ns}$ after laser irradiation. After the peak maximum, it rapidly reduced coincidentally with decreasing laser intensity. The maximum electrical conductance increased as the laser energy increased. It means that the silicon films were rapidly melted into a deep region by laser heating with a high intensity. Very rapid solidification was observed at $430 \mathrm{~mJ} / \mathrm{cm}^{2}$. High energy laser irradiation induced melting of silicon films in the whole thickness. Molten silicon films remained in the liquid state and the latent heat was not released when they cooled below the melting temperature (undercooling). The undercooled liquid silicon rapidly solidified and the latent heat was released simultaneously from the whole thickness [16]. Figure $1 \mathrm{~b}$ shows the maximum electrical conductance per unit area as a function of laser energy. The threshold energy of increase in the electrical conductance was determined by the melting point of silicon $\left(1412^{\circ} \mathrm{C}\right)$. The increasing rate of the electrical conductance means that the increasing rate of melting depth with laser energy is indicated. It was naturally governed by the latent heat energy of $4171 \mathrm{~J} / \mathrm{cm}^{3}$ for
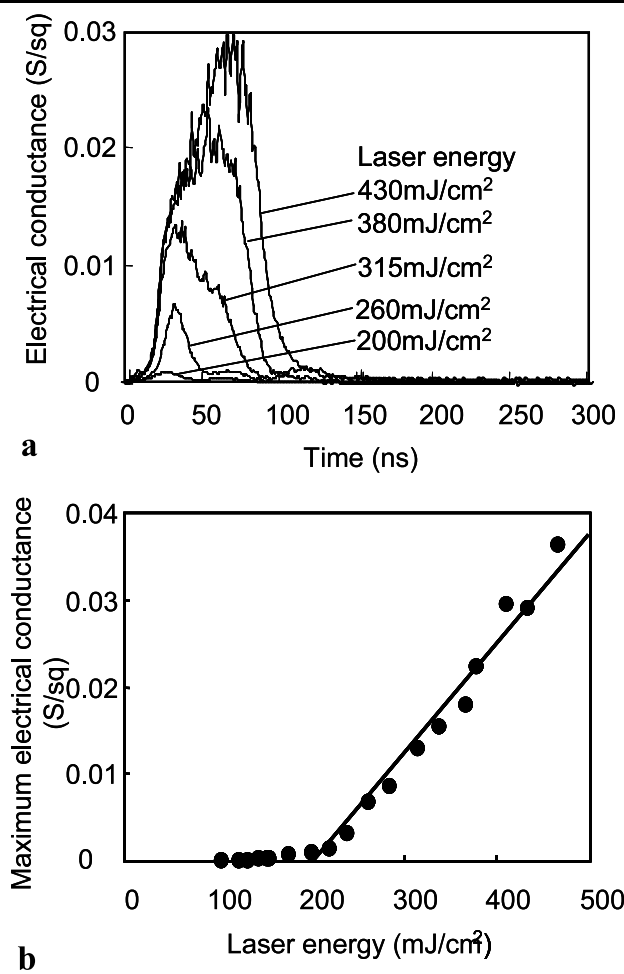

Fig. 1 Transient electrical conductance per unit area with time for 50-nm-thick Si films (a) and the maximum electrical conductance per unit area as a function of laser energy (b). A 308-nm pulsed $\mathrm{XeCl}$ excimer laser with $30 \mathrm{~ns}$ FWHM was irradiated at $0 \mathrm{~ns}$ at room temperature

crystalline Si. Figure 1 indicates that the melting point and the latent heat govern the melting properties.

\section{Structural and electrical properties}

Fine-grain and disordered structures were observed near the crystallization threshold by a transmission electron microscope (TEM) [17]. The average grain size increased and disordered regions decreased as the laser energy density increased. The grain size of about $0.1 \mu \mathrm{m}$ was observed at a laser energy density of $400 \mathrm{~mJ} / \mathrm{cm}^{2}$ for 50 -nm-thick silicon films. The preferential crystalline orientation of the laser crystallized silicon films was (111), which was observed by $\mathrm{X}$-ray diffraction because the interface control growth progresses from the nucleation sites at the bottom toward the top surface and the growth surface has the preferential crystalline orientation of (111) [17].

In general, thin films on foreign substrates are subjected to stress. It is well known that pulsed laser crystallized silicon films on glass substrates sustain a tensile stress [18]. Strong tensile stress is introduced by the deposited silicon film rather than by the pulsed-laser crystallized silicon film. Pulsed-laser crystallization maintains the existing stress at 


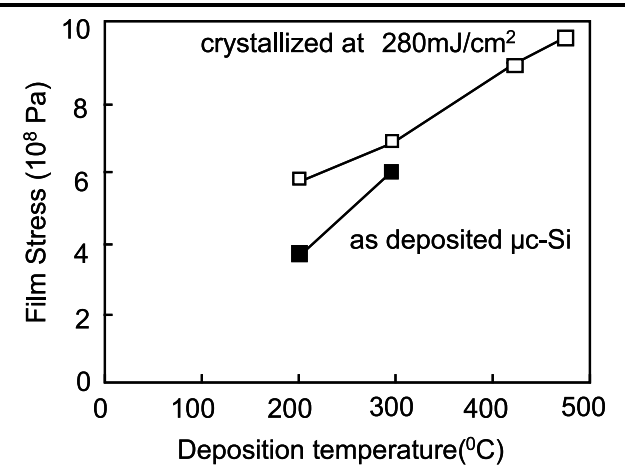

Fig. 2 Tensile film stress as a function of deposition temperatures for as-deposited and laser-annealed samples. 50-nm-thick silicon films formed on quartz substrates at 200 and $300^{\circ} \mathrm{C}$ were microcrystalline and deposited by PECVD, while the films formed at temperatures above $300^{\circ} \mathrm{C}$ were amorphous and deposited by LPCVD

the growth sites in the bottom region of the silicon film. Figure 2 shows the tensile film stress as a function of deposition temperatures from as-deposited and laser-annealed samples. The silicon films formed on quartz substrates at 200 and $300^{\circ} \mathrm{C}$ were microcrystalline and deposited by plasma enhanced chemical vapor deposition (PECVD), while the films formed at temperatures above $300^{\circ} \mathrm{C}$ were amorphous and deposited by low pressure chemical vapor deposition (LPCVD). Stokes Raman scattering spectra associated with the optical phonon of crystalline silicon were measured at room temperature. By comparing the peak wave number of the optical phonon obtained from silicon films and that obtained from a stress-free bulk silicon crystal, the strength of film stress was estimated [18, 19]. The as-deposited microcrystalline silicon films had the initial film stress induced during film deposition. After laser treatment, the tensile stress caused by laser irradiation was estimated as $2.7 \times 10^{8}$ and $1.5 \times 10^{8} \mathrm{~Pa}$ for the 200 and $300^{\circ} \mathrm{C}$ deposited films, respectively. The film stress increased from $3.5 \times 10^{8}$ to $9.7 \times 10^{8} \mathrm{~Pa}$ as the deposition temperature increased. These results show that the stress in the films changes little with the laser irradiation and significant tensile stress in silicon films is created during film formation. Tensile stress reduces the effective mass of the electrons and holes and it increases the carrier mobility [20]. The property of tensile stress of polySi films formed on quartz substrates is attractive for TFTs with a high carrier mobility.

Kitahara et al. precisely characterized the distribution of film stress of the laser crystallized silicon films using microRaman spectroscopy with a high spatial resolution [19]. The map of peak frequency shift indicated that the tensile stress is accumulated in grains and relaxed at grain boundaries. The tensile stress is estimated to be $1 \times 10^{9} \mathrm{~Pa}$ at the central region and $7 \times 10^{8} \mathrm{~Pa}$ at grain boundaries. In contrast, the density of electrically active defect states is concentrated at grain boundaries and few defects exist in grains.
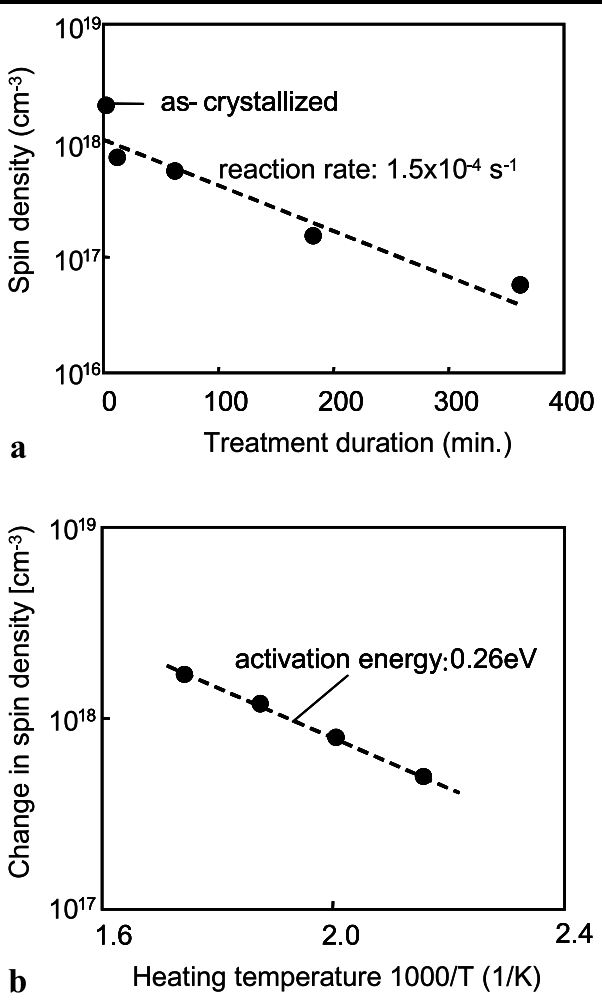

Fig. 3 Spin density as a function of the duration of heat treatment with $1.3 \times 10^{6} \mathrm{~Pa} \mathrm{H}_{2} \mathrm{O}$ vapor at $260^{\circ} \mathrm{C}$ for 50 -nm-thick poly-Si films formed by $\mathrm{XeCl}$ excimer laser irradiation at an energy density of $305 \mathrm{~mJ} / \mathrm{cm}^{2}$ (a) and spin density as a function of heating temperature for heat treatment with $1.3 \times 10^{6} \mathrm{~Pa} \mathrm{H}_{2} \mathrm{O}$ vapor for $3 \mathrm{~h}(\mathbf{b})$

Laser crystallized silicon films have a serious density of defect states at grain boundaries [21]. Defects trap free carriers so that they affect carrier transport in polycrystalline films. Reduction of defects by post laser annealing is important for good TFT characteristics. Plasma hydrogenation has been widely investigated to terminate silicon dangling bonds with hydrogen atoms and reduce the density of electrically active defects [22-25]. Oxygen plasma treatment is also effective to reduce the density of defects [26]. The silicon dangling bonds are oxidized by oxygen atoms and then they are not sensitive for carrier trapping. High-pressure $\mathrm{H}_{2} \mathrm{O}$ vapor heat treatment has also been developed for defect reduction at low processing temperature $[27,28]$.

Figure 3 a shows the spin density as a function of the duration of heat treatment with $1.3 \times 10^{6} \mathrm{~Pa} \mathrm{H}_{2} \mathrm{O}$ vapor at $260^{\circ} \mathrm{C}$ for 50-nm-thick poly-Si films formed by $\mathrm{XeCl}$ excimer laser irradiation at an energy density of $305 \mathrm{~mJ} / \mathrm{cm}^{2}$. The ascrystallized films had a high spin density of $2.0 \times 10^{18} \mathrm{~cm}^{-3}$ owing to the dangling bonds localized at grain boundaries. The spin density was reduced to $6.5 \times 10^{16} \mathrm{~cm}^{-3}$ by increasing the treatment duration to $6 \mathrm{~h}$. The dangling bonds were effectively passivated by heat treatment with high-pressure $\mathrm{H}_{2} \mathrm{O}$ vapor. The decrease in spin density was similar to an exponential decay with a single time constant of approxi- 
mately $110 \mathrm{~min}$, as shown in Fig. 3a. This indicates that the defect reduction is governed by the pseudo-first-order reaction between the densities of dangling bonds and $\mathrm{H}_{2} \mathrm{O}$ molecules incorporated into the silicon films. Figure $3 \mathrm{~b}$ shows the change in spin density by heat treatment with $1.3 \times 10^{6} \mathrm{~Pa}$ $\mathrm{H}_{2} \mathrm{O}$ vapor for $3 \mathrm{~h}$ as a function of heating temperature. The change in spin density was obtained by subtracting the spin density after $\mathrm{H}_{2} \mathrm{O}$ vapor annealing from the initial spin density. It increased as the heating temperature increased. A high temperature effectively reduced the spin density. The change in spin density was also similar to a single exponential decay, as shown in Fig. 3b. It means that the reduction rate of the spin density is proportional to the spin density. The activation energy $E$ was estimated to be $0.26 \pm 0.1 \mathrm{eV}$ by fitting the single exponential curve to the change in spin density shown in Fig. 3b. It gives the reaction rate constant $F$ in the simple equation $F=A \exp (-E / k T)$, where $A$ is the pre-exponential factor, $k$ is the Boltzmann constant and $T$ is the absolute temperature for heat treatment. The reaction rate increases with heating temperature. The reaction rate was the reciprocal time constant of the exponential decay of the spin density with time, as shown in Fig. 3. The reaction rate was $1.5 \times 10^{-4} \mathrm{~s}^{-1}\left(=1 / 110\right.$ [min]) for $260^{\circ} \mathrm{C}$ treatment with $1.3 \times 10^{6} \mathrm{~Pa} \mathrm{H}_{2} \mathrm{O}$ vapor. The pre-exponential factor $A$ was therefore estimated to be $0.04 \mathrm{~s}^{-1}$ by the obtained reaction rates and activation energies. The estimations result in the spin density $I$ decreasing with time $t$ as $I=I_{0} \exp \{-0.04 \exp (-0.26 / k T) t\}$ for heat treatment with $1.3 \times 10^{6} \mathrm{~Pa} \mathrm{H}_{2} \mathrm{O}$ vapor, where $I_{0}$ is the initial spin density. The low activation energy allows defect-state reduction at a low temperature. However, the pre-exponential factor was low. A long time is necessary for reducing the defect density. Our recent study revealed that the oxygen concentration increased after high-pressure $\mathrm{H}_{2} \mathrm{O}$ vapor heat treatment, and that the hydrogen concentration decreased [29]. These results indicate a possibility that dangling bonds are well oxidized and oxygen atoms terminate dangling bonds at grain boundaries.

\section{Poly-Si TFT fabricated by excimer laser crystallization and its characteristics}

In order to apply laser crystallization to fabrication of polySi TFTs with high performances, defect passivation is necessary for the $\mathrm{SiO}_{2} / \mathrm{Si}$ interface as well as silicon films. Because $\mathrm{SiO}_{2}$ films formed at low temperatures are not thermally relaxed states in general, defect states can be generated at the $\mathrm{SiO}_{2} / \mathrm{Si}$ interface. Several technologies have been developed in order to form $\mathrm{SiO}_{2}$ with a low density of defect states at low temperatures. There have been, for example, electron cyclotron resonance plasma CVD, remote plasma CVD, plasma sputtering and molecular beam deposition. We

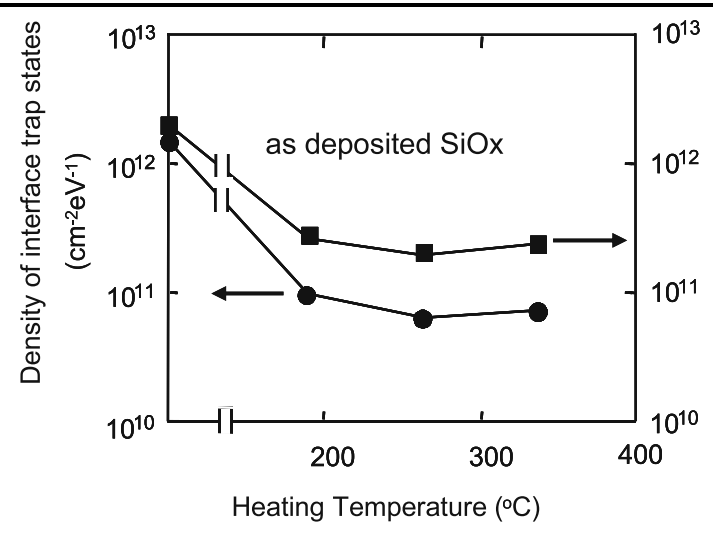

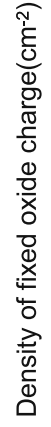

Fig. 4 Densities of interface trap states and positive fixed charges as a function of the duration of $1.3 \times 10^{6} \mathrm{~Pa} \mathrm{H}_{2} \mathrm{O}$ vapor heat treatment at $260^{\circ} \mathrm{C}$ for the MOS capacitor with 50 -nm-thick $\mathrm{SiO}_{2}$ formed by the molecular beam deposition method

have applied high-pressure $\mathrm{H}_{2} \mathrm{O}$ heat treatment in order to improve $\mathrm{SiO}_{2} / \mathrm{Si}$ interface properties [27]. Through investigation of high- and low-frequency capacitance-voltage $(C-$ $V$ ) characteristics for a metal-oxide-semiconductor (MOS) capacitor structure, we revealed that $\mathrm{H}_{2} \mathrm{O}$ vapor heat treatment is effective to reduce defect states in $\mathrm{SiO}_{2}$ films deposited at low temperature. Figure 4 shows the densities of interface trap states and positive fixed charges as a function of the duration of $1.3 \times 10^{6} \mathrm{~Pa} \mathrm{H}_{2} \mathrm{O}$ vapor heat treatment at $260^{\circ} \mathrm{C}$ for the MOS capacitor with 50-nm-thick $\mathrm{SiO}_{2}$ formed by the molecular beam deposition method. The density of interface trap states for the initial $\mathrm{SiO}_{2}$ film was evaluated to be $3.3 \times 10^{12} \mathrm{~cm}^{-2}$. The $\mathrm{H}_{2} \mathrm{O}$ vapor heat treatment reduced the density of interface trap states with increasing treatment duration. The interface trap state density was effectively decreased to $5.1 \times 10^{10} \mathrm{~cm}^{-2} \mathrm{eV}^{-1}$ by the treatment at $260^{\circ} \mathrm{C}$ for $3 \mathrm{~h}$. The density of fixed oxide charges was also reduced from $2.1 \times 10^{11}$ (initial) to $1.3 \times 10^{11}$ $\mathrm{cm}^{-2}$ by the treatment for $3 \mathrm{~h}$, as shown in Fig. 4 .

Poly-Si TFTs were fabricated by the pulsed excimer laser crystallization and the defect reduction method [30,31]. $7 \times 10^{20} \mathrm{~cm}^{-3}$ phosphorus with a thickness of $30 \mathrm{~nm}$ was first formed on glass substrates at $330^{\circ} \mathrm{C}$ using plasma enhanced chemical vapor deposition (PECVD). The doped films were removed at the channel region with a length of $25 \mu \mathrm{m}$ by etching and they were used as dopant sources for forming source and drain regions. 25-nm-thick undoped a-Si:H films were then deposited using PECVD over the whole area. The silicon layers were crystallized by irradiation of a 30-ns pulsed $\mathrm{XeCl}$ excimer laser at $300 \mathrm{~mJ} / \mathrm{cm}^{2}$. Undoped crystallized regions were used as the channel region. Source and drain regions were simultaneously formed through diffusion of phosphorus atoms into the overlaying silicon layer during the laser crystallization. The melt duration of silicon during laser crystallization was shorter than $100 \mathrm{~ns}$ so that the diffusion distance of the dopant atoms 


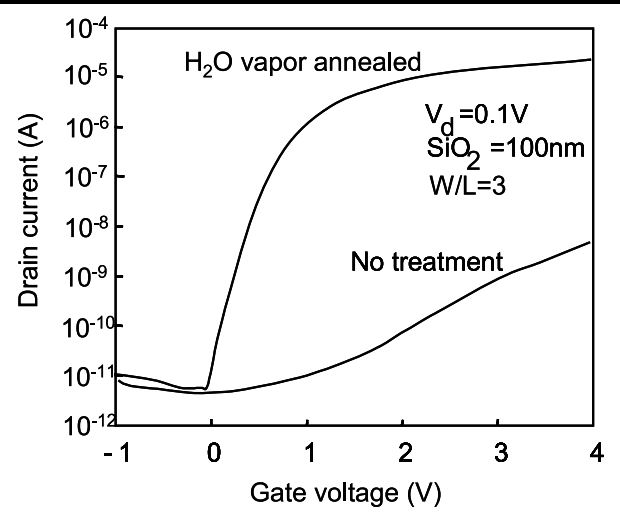

Fig. 5 Transfer characteristics of poly-Si TFTs fabricated with no defect reduction and with heat treatment with $1.3 \times 10^{6} \mathrm{~Pa} \mathrm{H}_{2} \mathrm{O}$ vapor at $260^{\circ} \mathrm{C}$ for $3 \mathrm{~h}$ applied after laser crystallization and TFT fabrication

was at most $60 \mathrm{~nm}$ in liquid silicon [32] and the $25-\mu \mathrm{m}$ channel length hardly changed. After laser crystallization, silicon films were heated in $1.3 \times 10^{6} \mathrm{~Pa} \mathrm{H}_{2} \mathrm{O}$ vapor for $3 \mathrm{~h}$ for reduction in defects of the silicon films. The silicon films were then patterned by etching for isolation. The molecular beam deposition method was used for formation of the gate insulator. The 100-nm-thick $\mathrm{SiO}_{2}$ films were then deposited at room temperature using evaporation of $\mathrm{SiO}$ powders in oxygen radicals produced by induction-coupled plasma. Gate, drain and source electrodes were formed with Al metal. After fabrication of the TFT structure, the samples were heated in $1.3 \times 10^{6} \mathrm{~Pa} \mathrm{H}_{2} \mathrm{O}$ vapor for $3 \mathrm{~h}$ for improving $\mathrm{SiO}_{2} / \mathrm{Si}$ interface characteristics. Figure 5 shows the transfer characteristics of the poly-Si TFTs. The TFT fabricated with no defect reduction showed a very low drain current and a high threshold voltage because of a carrier-trapping effect by defects. On the other hand, heat treatment with high-pressure $\mathrm{H}_{2} \mathrm{O}$ vapor markedly increased the drain current in the low gate voltage region because of defect reduction. The mobility increased to $600 \mathrm{~cm}^{2} / \mathrm{V} \mathrm{s}$ and the threshold voltage decreased to 0.9 V. Figure 6 shows changes in the carrier mobility and the threshold voltage with $1.3 \times 10^{6} \mathrm{~Pa} \mathrm{H}_{2} \mathrm{O}$ vapor heat treatment for $3 \mathrm{~h}$. Although the carrier mobility was very low and the threshold voltage was high for a poly-Si TFT fabricated with no $\mathrm{H}_{2} \mathrm{O}$ vapor heat treatment because of a high density of defect states, the carrier mobility was increased to $360 \mathrm{~cm}^{2} / \mathrm{V} \mathrm{s}$ and the threshold voltage was decreased to $2.3 \mathrm{~V}$ by $\mathrm{H}_{2} \mathrm{O}$ vapor heat treatment after laser crystallization. Defect reduction in poly-Si was essential for fabrication of TFTs with high performances. Additional $\mathrm{H}_{2} \mathrm{O}$ vapor heat treatment after TFT fabrication further increased the carrier mobility to $600 \mathrm{~cm}^{2} / \mathrm{V} \mathrm{s}$ and reduced the threshold voltage to $0.9 \mathrm{~V}$. Defect reduction at the $\mathrm{SiO}_{2} / \mathrm{Si}$ interface was also important to improve TFT characteristics. The numerical analysis of transfer characteristics resulted in TFTs after defect reduction treatment still having defects. Defects were mainly tail-type states with a

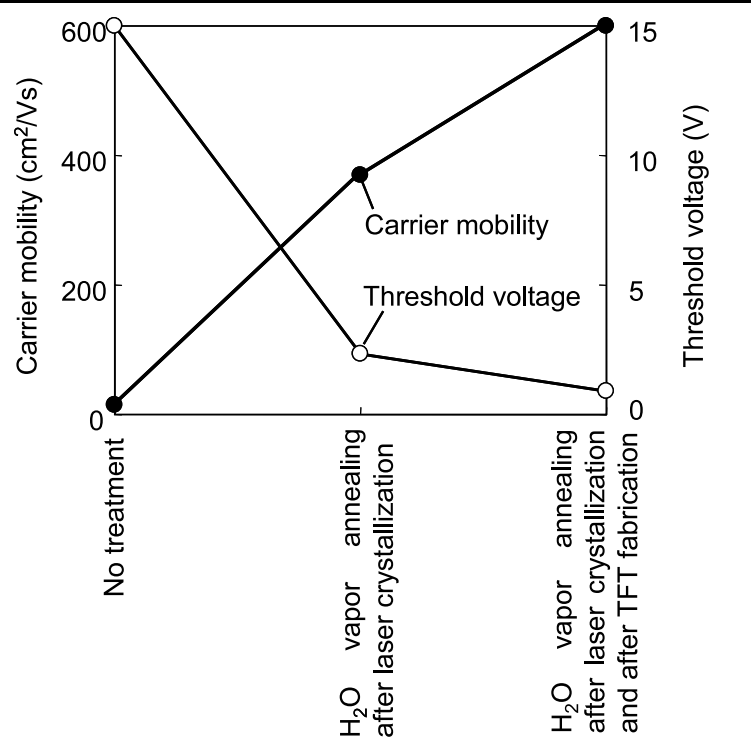

Fig. 6 Changes in the carrier mobility and the threshold voltage with $1.3 \times 10^{6} \mathrm{~Pa} \mathrm{H}_{2} \mathrm{O}$ vapor heat treatment for $3 \mathrm{~h}$

width of $0.2 \mathrm{eV}$ and the density of $2 \times 10^{12} \mathrm{~cm}^{-2}$, which were located in silicon. The defect states were occupied by $1 \times 10^{11} \mathrm{~cm}^{-2}$ at the threshold voltage at $0.9 \mathrm{~V}$ because the Fermi level is located at $0.9 \mathrm{eV}$ measured from the valenceband edge. Most of the defect states stay just below the conduction-band edge. Although the tail-type states allow a low threshold voltage for the drain-current increase, the numerical analysis suggests that there was still a high density of unoccupied defect states for gate voltages above the threshold voltage.

\section{Formation of large crystalline grains}

Grain growth in the lateral direction is important for formation of large crystalline grains in thin silicon films. Many laser crystallization technologies have been investigated for lateral grain growth in order to look for fabrication of singlecrystalline TFTs with no grain-boundary effect. Im and Kim have reported a rapid lateral grain growth of $\sim 5 \mu \mathrm{m}$ by a single-pulse irradiation of an excimer laser with an energy just below the complete melting threshold energy without heating the substrate [33]. Oh et al. reported crystalline grain growth of $\sim 5 \mu \mathrm{m}$ using a phase-shift mask in order to make a spatial distribution of the excimer laser intensity for generation of a temperature distribution [34]. Van der Wilt et al. achieved the control of crystalline nucleation by thick silicon films and fabricated crystalline grains that were spatially controlled [35]. They fabricated poly-Si TFTs with an electron mobility of $345 \mathrm{~cm}^{2} / \mathrm{V}$ s in their silicon films with a processing temperature of $545^{\circ} \mathrm{C}$. Okumura and co-workers developed a comb-shaped excimer laser beam to induce a temperature gradient in the lateral direction. They achieved 
grain growth $5-\mu \mathrm{m}$ long and a TFT with an electron mobility of $677 \mathrm{~cm}^{2} / \mathrm{V}$ s with a processing temperature of $450^{\circ} \mathrm{C}$ [36]. Han and co-workers reported 5- $\mu \mathrm{m}$-long lateral grain growth by an excimer laser using air-gap strips below silicon films. They also fabricated a TFT with an electron mobility of $452 \mathrm{~cm}^{2} / \mathrm{V} \mathrm{s}$ [37].

Laser heating using a continuous-wave $(\mathrm{CW})$ laser beam with a Gaussian intensity profile is also attractive for meltinduced crystallization of silicon films formed on glass substrates $[38,39]$. The peripheral region of the molten zone is cooler than the central region and the crystalline growth will start from the molten polycrystalline silicon and proceed to the central region. Unmolten silicon at the boundary of the molten zone acts as a seed for the crystallizing silicon. A high-power diode-pumped solid-state $\mathrm{CW}$ laser $\left(\mathrm{Nd}: \mathrm{YVO}_{4}\right)$ has been recently developed. Hara et al. applied the laser to crystallization of silicon films [40]. They investigated the condition of lateral crystallization with large grains $(\sim 20 \mu \mathrm{m})$. They fabricated a poly-Si TFT with an electron mobility higher than $566 \mathrm{~cm}^{2} / \mathrm{V}$ s and a hole mobility of $200 \mathrm{~cm}^{2} / \mathrm{V}$ s in the silicon films with large crystalline grains. Tai et al. developed a crystallization method using an excimer laser for crystalline nucleation formation and a $\mathrm{CW}$ green laser for lateral crystallization from the nucleation sites. They reported good TFTs with an electron mobility of $460 \mathrm{~cm}^{2} / \mathrm{V} \mathrm{s}$ [41].

\section{Infrared laser annealing}

We have proposed laser crystallization of silicon films by an irradiation laser using diamond-like-carbon (DLC) films as the photo-absorption layer [42, 43]. DLC has been widely utilized for technological and industrial applications. Its optical absorption property is also attractive. DLC has low refractive indices of 1.3-1.9 and can have a high extinction coefficient of $\sim 0.8$ for wavelengths from 250 to $1000 \mathrm{~nm}$. Therefore, infrared laser diodes or YAG lasers can be used for crystallization of silicon films by the assistance of optical absorption with DLC, while silicon films have almost no optical absorbance in the infrared wavelength range. The power intensity of a continuous-wave (CW) laser diode is very stable and easily modulated by controlling the electrical current. Especially, a near-infrared laser diode has a markedly high durability with a lifetime longer than $10000 \mathrm{~h}$. The laser diodes have a high energy conversion efficiency above $50 \%$. They can be easily assembled and give a power intensity higher than $10 \mathrm{~kW}$.

A fiber-coupled continuous-wave laser diode with a wavelength of $940 \mathrm{~nm}$ and a beam spot size of $180 \mu \mathrm{m}$ was used for annealing samples. 50-nm-thick amorphous silicon (a-Si) films were coated with graphitic DLC films with thickness of $200 \mathrm{~nm}$ by the unbalanced magnetron

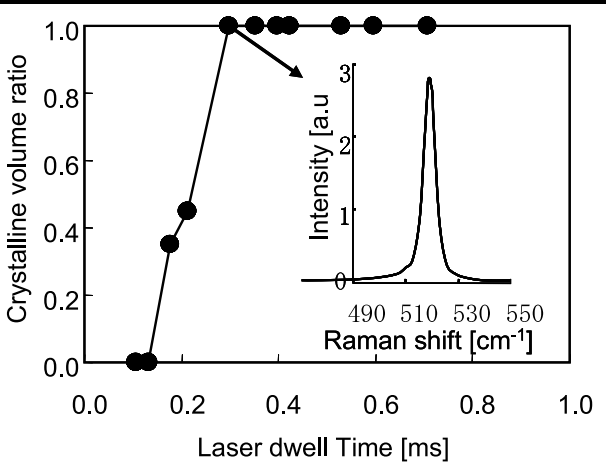

Fig. 7 Crystalline volume ratio of 50-nm-thick silicon films formed on quartz substrates as a function of the $940-\mathrm{nm}$ CW laser dwell time at a laser power intensity of $24.7 \mathrm{~kW} / \mathrm{cm}^{2}$. The crystalline volume ratio was obtained from analysis of the optical phonon peak in Raman scattering spectra

sputtering (UBMS) method [44]. The formation of 200-nmthick DLC films resulted in an optical absorbance of 0.64 at $940 \mathrm{~nm}$. Laser irradiation was conducted with different laser dwell times controlled by the beam scanning velocity. The carbon layer was removed by oxygen plasma treatment. Figure 7 shows the crystalline volume ratio as a function of the laser dwell time at a laser power intensity of $24.7 \mathrm{~kW} / \mathrm{cm}^{2}$. The crystalline volume ratio was obtained from analysis of the optical phonon peak in Raman scattering spectra. Crystallization was observed at a laser dwell time of $0.18 \mathrm{~ms}$. The crystalline volume ratio increased as the laser dwell time increased to $0.3 \mathrm{~ms}$. A sharp phonon peak was observed with a high crystalline volume ratio of 1.0 for laser dwell times longer than $0.3 \mathrm{~ms}$, as shown in the inset. This suggests that the DLC films effectively absorbed the 940-nm infrared laser light and were heated to a sufficiently high temperature to crystallize silicon films. Electron backscattering measurement revealed that the crystalline grain growth with a size of $3 \mu \mathrm{m}$ was achieved by laser annealing for $0.4 \mathrm{~ms}$.

Moreover, the present method was applied for rapid activation of impurities [45]. The activation of impurity atoms using rapid annealing technologies is important for the formation of shallow junctions to fabricate a shallow source/drain extension region with a depth of $10 \mathrm{~nm}$ in MOS transistor devices for a 45-nm node [46-48]. It has not been realized by conventional rapid thermal annealing (RTA).

Thin silicon dioxide $\left(\mathrm{SiO}_{2}\right)$ layers with a thickness of $7.9 \mathrm{~nm}$ were grown over n-type and p-type $\mathrm{Si}(100)$ substrates with resistivities of $10-15 \Omega \mathrm{cm}$ prior to an implantation operation as screen oxide layers. The ion implantation of boron (B) and phosphorus (P) impurities was conducted using $\mathrm{P}$ and $\mathrm{BF}_{2}$ ions. The ion energies were $7.5 \mathrm{keV}$ for $\mathrm{P}^{+}$and $10 \mathrm{keV}$ for $\mathrm{BF}_{2}^{+}$. The doping concentration was $1.5 \times 10^{15} \mathrm{~cm}^{-2} .7 .5 \times 10^{14} \mathrm{~cm}^{-2}$ phosphorus and boron atoms were incorporated into silicon. DLC films with a thickness of $200 \mathrm{~nm}$ were then formed on the silicon surface by UBMS. The samples were irradiated with a $940-\mathrm{nm}$ 

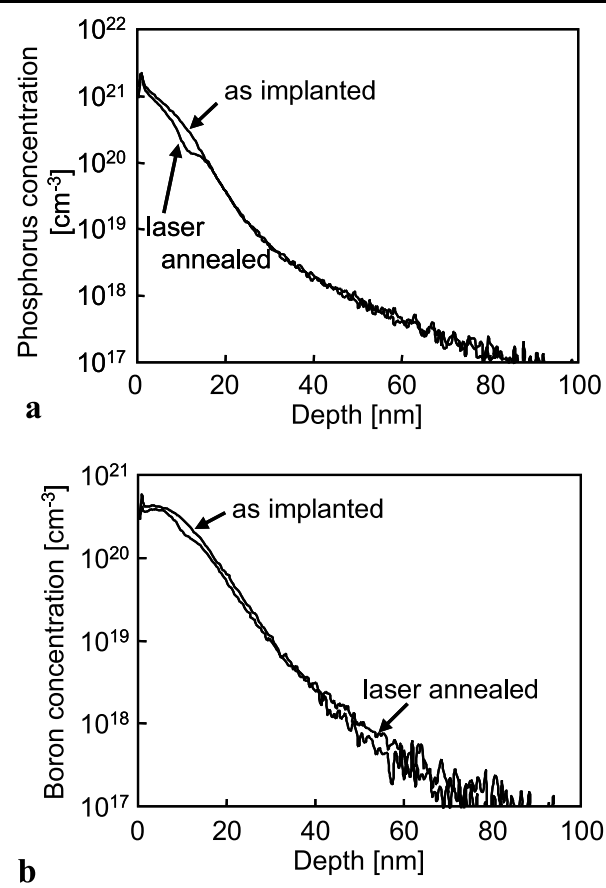

Fig. 8 In-depth profiles of phosphorus (a) and boron atoms (b) in as-implanted and laser-annealed cases. Similar in-depth profiles were observed between the as-implanted and laser-annealed cases. Implantation with $7.5-\mathrm{keV} \mathrm{P}^{+}$and $10-\mathrm{keV} \mathrm{BF}_{2}{ }^{+}$ions with a concentration of $1.5 \times 10^{15} \mathrm{~cm}^{-2}$ was carried out to silicon wafers coated with $7.9-\mathrm{nm}$ thermally grown $\mathrm{SiO}_{2}$ layers

laser with a peak power density of $81 \mathrm{~kW} / \mathrm{cm}^{2}$. The dwell time of the laser beam was $2.6 \mathrm{~ms}$. After laser irradiation, the carbon layers were removed by oxygen plasma treatment. The screen oxide layers were also removed using HF solutions. Figure 8 shows the in-depth profiles of phosphorus (a) and boron atoms (b) in as-implanted and laserannealed cases. Similar in-depth profiles were observed between the as-implanted and laser-annealed cases. The depth at $1 \times 10^{18} \mathrm{~cm}^{-3}$ was 45 and $49 \mathrm{~nm}$ for phosphorus and boron implantation, respectively, in the as-implanted case. On the other hand, it was 46 and $52 \mathrm{~nm}$ for phosphorus and boron implantation, respectively, in the laser-annealed case. Only 3-nm diffusion was observed. The Raman scattering measurement revealed that laser irradiation at $81 \mathrm{~kW} / \mathrm{cm}^{2}$ for $2.6 \mathrm{~ms}$ completed recrystallization at the surface regions associated with reduction of the disordered broad band around $480 \mathrm{~cm}^{-1}$ caused by ion implantation. The sheet resistance was reduced to 242 and $531 \Omega /$ sq for phosphorus and boron doping, respectively. Highly efficient activation was achieved with very low diffusion of dopant atoms by laser annealing. We consider that the silicon surface regions were heated to a very high temperature by laser annealing, causing the recrystallization of implanted regions. By heatflow calculation, we estimated that the heating duration for temperatures above $1300^{\circ} \mathrm{C}$ was about $1.5 \mathrm{~ms}$. The short heating duration kept the diffusion length low as shown in
Fig. 8. Millisecond heat treatment will be important in activating the implanted regions while keeping initial dopant concentration profiles.

\section{Summary}

Rapid laser crystallization of silicon films was discussed for forming polycrystalline silicon thin films used to fabricate poly-Si TFTs. A pulsed laser rapidly heats silicon films and melts them. Rapid melt-regrowth of silicon films results in poly-Si films with small crystalline grains $\sim 0.1 \mu \mathrm{m}$ and a preferential orientation of (111). We revealed that the stress of laser crystallized films was mainly determined by stress at the bottom interface depending on the film-formation temperature. Electrical properties of poly-Si films were governed by defects located at grain boundaries. Treatments of hydrogen plasma, oxygen plasma and high-pressure $\mathrm{H}_{2} \mathrm{O}$ vapor were developed in order to reduce the density of defect states. TFT fabrication was reported using high-pressure $\mathrm{H}_{2} \mathrm{O}$ vapor heat treatment. A low threshold voltage of $0.9 \mathrm{~V}$ and a high mobility of $600 \mathrm{~cm}^{2} / \mathrm{V} \mathrm{s}$ resulted from defect reduction in poly-Si silicon and gate insulator/silicon interfaces. Recent developments in laser crystallization methods with pulsed and continuous-wave $(\mathrm{CW})$ lasers were reviewed. The controls of the heat flow and the crystalline nucleation have resulted in lateral crystalline grain growth in a few micrometers. Those techniques are important for fabrication of large crystalline grains and high-performance TFTs. We reported an annealing method using a high-power infrared semiconductor laser. Silicon films were successfully crystallized by the infrared laser using a carbon optical absorption layer. Grain growth in a few microns was achieved. The activation of the silicon implanted with phosphorus and boron atoms was achieved by laser annealing for samples implanted with $\mathrm{P}^{+}$atoms at $7.5 \mathrm{keV}$ and $\mathrm{BF}_{2}{ }^{+}$ atoms at $10 \mathrm{keV}$ with a concentration of $1.5 \times 10^{15} \mathrm{~cm}^{-2}$ through the 7.9-nm screen oxide layers. Laser annealing at $81 \mathrm{~kW} / \mathrm{cm}^{2}$ for $2.6 \mathrm{~ms}$ completely recrystallized the implanted regions while keeping the initial in-depth profiles within a diffusion length of $3 \mathrm{~nm}$. The resistance was reduced to 242 and $531 \Omega /$ sq for phosphorus and boron doping.

\section{References}

1. S. Uchikoga, N. Ibaraki, Thin Solid Films 383, 19 (2001)

2. S. Inoue, K. Sadao, T. Ozawa, Y. Kobashi, H. Kwai, T. Kitagawa, T. Shimoda, in Tech. Dig. IEDM (2000), p. 197

3. K. Shibata, H. Takahashi, in Proc. Int. Workshop on Active Matrix Liquid Crystal Displays'01, Tokyo (2001), p. 219

4. D.P. Gosain, T. Noguchi, A. Machida, S. Usui, in Proc. in Workshop on Active Matrix Liquid Displays'99, Tokyo (1999), p. 239 
5. T. Sameshima, S. Usui, M. Sekiya, IEEE Electron Device Lett. 7, $276(1986)$

6. K. Sera, F. Okumura, H. Uchida, S. Itoh, S. Kaneko, K. Hotta, IEEE Trans. Electron Devices 36, 2868 (1989)

7. T. Serikawa, S. Shirai, A. Okamoto, S. Suyama, Jpn. J. Appl. Phys. 28, L1871 (1989)

8. A. Kohno, T. Sameshima, N. Sano, M. Sekiya, M. Hara, IEEE Trans. Electron Devices 42, 251 (1995)

9. P.L. Liu, R. Yen, N. Bloembergen, R.T. Hodson, Appl. Phys. Lett. 34, 864 (1979)

10. R.F. Wood, C.E. Giles, Phys. Rev. B 23, 2923 (1981)

11. H.S. Carslaw, J.C. Jaeger, Conduction of Heat in Solids (Oxford University Press, Oxford, 1959), Chaps. 2 and 10

12. A. Goldsmith, T.E. Waterman, H.J. Hirschorn, Handbook of Thermophysical Properties of Solid Materials, vols. 1 and 3 (Pergamon, New York, 1961)

13. G.J. Galvin, M.O. Thompson, J.W. Mayer, R.B. Hammond, N. Paulter, P.S. Peercy, Phys. Rev. Lett. 48, 33 (1982)

14. T. Sameshima, M. Hara, S. Usui, Jpn. J. Appl. Phys. 28, 1789 (1989)

15. T. Sameshima, H. Watakabe, H. Kanno, T. Sadoh, M. Miyao, Thin Solid Films 487, 67 (2005)

16. T. Sameshima, M. Hara, S. Usui, Jpn. J. Appl. Phys. Lett. 29, 1363 (1990)

17. S. Higashi, $\mathrm{PhD}$ dissertation, Tokyo University of Agriculture and Technology (2001), Chap. 3

18. S. Higashi, N. Andoh, K. Kamisako, T. Sameshima, Jpn. J. Appl. Phys. 40, 731 (2001)

19. K. Kitahara, A. Moritani, A. Hara, M. Okabe, Jpn. J. Appl. Phys. 38, L1312 (1999)

20. T. Mizuno, S. Takagi, N. Sugiyama, H. Satake, K. Kurobe, A. Toriumi, IEEE Electron Device Lett. 21, 230 (2000)

21. T. Sameshima, K. Saitoh, N. Aoyama, S. Higashi, M. Kondo, A. Matsuda, Jpn. J. Appl. Phys. 38, 1892 (1999)

22. R.A. Ditizio, G. Liu, S.J. Fonash, B.-C. Hseih, D.W. Greve, Appl. Phys. Lett. 56, 1140 (1990)

23. I.-W. Wu, A.G. Lewis, T.-Y. Huang, A. Chiang, IEEE Electron Device Lett. 10, 123 (1989)

24. U. Mitra, B. Rossi, B. Khan, J. Electrochem. Soc. 138, 3420 (1991)

25. D. Jousse, S.L. Delage, S.S. Iyer, Philos. Mag. B 63, 443 (1991)
26. Y. Tsunoda, T. Sameshima, S. Higashi, Jpn. J. Appl. Phys. 39, $1656(2000)$

27. T. Sameshima, M. Satoh, Jpn. J. Appl. Phys. 36, L687 (1997)

28. K. Asada, K. Sakamoto, T. Watanabe, T. Sameshima, S. Higashi, Jpn. J. Appl. Phys. 39, 3883 (2000)

29. T. Sameshima, H. Hayasaka, M. Maki, A. Masuda, T. Matsui, M. Kondo, Jpn. J. Appl. Phys. 46, 1286 (2007)

30. H. Watakabe, T. Sameshima, IEEE Trans. Electron Devices 49 , $2217(2002)$

31. H. Watakabe, T. Sameshima, Jpn. J. Appl. Phys. 41, L974 (2002)

32. T. Sameshima, M. Hara, S. Usui, Mater. Res. Soc. Symp. Proc. 158, 255 (1990)

33. J.S. Im, H.J. Kim, Appl. Phys. Lett. 63, 1969 (1993)

34. C.-H. Oh, M. Ozawa, M. Matsumura, Jpn. J. Appl. Phys. 37, L492 (1998)

35. P.Ch. van der Wilt, B.D. van Dijk, G.J. Bertens, R. Ishihara, C.I.M. Beenakker, Appl. Phys. Lett. 79, 1819 (2001)

36. M. Nakata, H. Okumura, H. Kanoh, H. Hayama, in Proc. AsiaDisplay/IMID'04, Tegu, Korea (2004), p. 412

37. C.H. Kim, I.H. Song, W.J. Nam, M.K. Han, IEEE Electron Device Lett. 23, 315 (2002)

38. T.J. Stultz, J.F. Gibbons, Appl. Phys. Lett. 39, 498 (1981)

39. K.F. Lee, J.F. Gibbons, K.C. Saraswat, T.I. Kamins, Appl. Phys. Lett. 35, 173 (1979)

40. A. Hara, F. Takeuchi, M. Takei, K. Suga, K. Yoshino, M. Chida, Y. Sano, N. Sasai, Jpn. J. Appl. Phys. 37, L5 (2002)

41. M. Tai, M. Hatano, S. Yamaguchi, T. Noda, P.S. Kee, T. Shiba, M. Ohkura, IEEE Trans. Electron Devices 51, 934 (2004)

42. T. Sameshima, N. Andoh, Jpn. J. Appl. Phys. 44, 7305 (2005)

43. N. Sano, M. Maki, N. Andoh, T. Sameshima, Mater. Res. Soc. Symp. Proc. 910, A14-02 (2006)

44. G. Viera, S. Huet, L. Boufendi, J. Appl. Phys. 90, 4175 (2001)

45. N. Sano, M. Maki, N. Andoh, T. Sameshima, Y. Matsuda, Y. Andoh, Jpn. J. Appl. Phys. 46, L620 (2007)

46. T. Ito, K. Suguro, M. Tamura, T. Taniguchi, Y. Ushiku, T. Iinuma, T. Itani, M. Yoshioka, T. Owada, Y. Imaoka, H. Murayama, T. Kusuda, in Ext. Abstr. 3rd Int. Workshop on Junction Technology (2002), p. 23

47. A. Shima, A. Hiraiwa, Jpn. J. Appl. Phys. 45, 5708 (2006)

48. K. Goto, T. Yamamoto, T. Kubo, M. Kase, Y. Wang, T. Lin, S. Talwar, T. Sugii, in Tech. Dig. IEDM (1999), p. 931 